\title{
Infection with street strain rabies virus induces modulation of the microRNA profile of the mouse brain
}

Pingsen Zhao ${ }^{1,2+}$, Lili Zhao ${ }^{2,3+}$, Kun Zhang ${ }^{1,2}$, Hao Feng ${ }^{2,3}$, Hualei Wang ${ }^{2}$, Tiecheng Wang ${ }^{2}$, Tao Xu ${ }^{4}$, Na Feng ${ }^{2}$, Chengyu Wang ${ }^{2}$, Yuwei Gao ${ }^{2}$, Geng Huang ${ }^{2}$, Chuan Qin', Songtao Yang ${ }^{2^{*}}$ and Xianzhu Xia ${ }^{1,2^{*}}$

\begin{abstract}
Background: Rabies virus (RABV) causes a fatal infection of the central nervous systems (CNS) of warm-blooded animals. Once the clinical symptoms develop, rabies is almost invariably fatal. The mechanism of RABV pathogenesis remains poorly understood. Recent studies have shown that microRNA (miRNA) plays an important role in the pathogenesis of viral infections. Our recent findings have revealed that infection with laboratory-fixed rabies virus strain can induce modulation of the microRNA profile of mouse brains. However, no previous report has evaluated the miRNA expression profile of mouse brains infected with RABV street strain.

Results: The results of microarray analysis show that miRNA expression becomes modulated in the brains of mice infected with street RABV. Quantitative real-time PCR assay of the differentially expressed miRNAs confirmed the results of microarray assay. Functional analysis showed the differentially expressed miRNAs to be involved in many immune-related signaling pathways, such as the Jak-STAT signaling pathway, the MAPK signaling pathway, cytokine-cytokine receptor interactions, and Fc gamma R-mediated phagocytosis. The predicted expression levels of the target genes of these modulated miRNAs were found to be correlated with gene expression as measured by DNA microarray and qRT-PCR.

Conclusion: RABV causes significant changes in the miRNA expression profiles of infected mouse brains. Predicted target genes of the differentially expression miRNAs are associated with host immune response, which may provide important information for investigation of RABV pathogenesis and therapeutic method.
\end{abstract}

Keywords: Street strain rabies virus, Brain infection, MicroRNA profiling, Gene profiling, Target prediction, Functional enrichment

\section{Background}

The rabies virus (RABV), a member of the family Rhabdoviridae, is a highly neurotropic virus that can cause fatal infections of the central nervous systems (CNS) of warm-blooded animals [1,2]. Although significant advances have been made in rabies prevention and control, the disease remains a major threat to public health. It

\footnotetext{
*Correspondence: yst10223@yahoo.com.cn; xiaxianzhu@gmail.com ${ }^{\dagger}$ Equal contributors

${ }^{2}$ Key Laboratory of Jilin Province for Zoonosis Prevention and Control, Institute of Military Veterinary, Academy of Military Medical Sciences, Changchun 130122, China

Institute of Laboratory Animal Sciences, Chinese Academy of Medical Sciences \& Peking Union Medical College, Beijing 100021, China

Full list of author information is available at the end of the article
}

causes 55,000 people die around the world every year [3]. Despite the catastrophic clinical outcome of RABV encephalomyelitis, the histopathological changes observed in the CNS are typically relatively mild, showing varying degrees of mononuclear inflammatory cell infiltration of the leptomenings, perivascular cuffing, microglial activation, and neuronophagia. Although there are several hypotheses under active study at present, the pathogenesis of the rabies virus has not yet been determined.

MiRNA (miRNA, miR) is endogenous $\approx 22$ nt RNA that negatively regulates gene expression by translational repression [4]. It binds to the complementary sequences in the mRNAs and blocks the translation or accelerates mRNA decay [5]. MiRNAs play key roles in cellular

\section{Biomed Central}

(c) 2012 Zhao et al.; licensee BioMed Central Ltd. This is an Open Access article distributed under the terms of the Creative Commons Attribution License (http://creativecommons.org/licenses/by/2.0), which permits unrestricted use, distribution, and reproduction in any medium, provided the original work is properly cited. 
processes such as development, differentiation, cell proliferation, and hematopoiesis [6-9]. Recently, evidence has demonstrated that cellular miRNAs exert regulatory functions in virus-host interactions [10,11]. It is becoming increasingly clear that miRNAs of cellular origin can positively or negatively influence viral infection. For example, miR-122 is indispensable to replication of the hepatitis $\mathrm{C}$ virus (HCV), whereas miR-196 and miR-296 substantially attenuate viral replication $[12,13]$. A recent study reported that miR-28, miR-125b, miR-150, miR223, and miR-382 inhibit replication of the human immunodeficiency virus (HIV) in CD4 $4^{+} \mathrm{T}$ cells [14].

Microarray analyses have been recently employed to detect changes in host miRNA expression, which can help reveal molecular pathways that govern viral pathogenesis. By using miRNA microarray profiling, researchers have observed differentially expressed patterns of cellular miRNAs in the lungs of mice infected with influenza virus [15]. Another study found miRNAs to be significantly regulated in mouse brains upon Venezuelan equine encephalitis virus (VEEV) infection [16]. Our own recent findings suggest that infection with laboratory-fixed rabies virus, ERA (Evelyn Rokitnicki Abelseth), can induce modulation of the microRNA profile of the mouse brain [17]. However, no report has yet been made regarding the assessment of the host miRNA expression profile in mouse brains upon infection with the street strain of RABV.

In this study, we performed an expression profile of cellular miRNAs in the brains of mice infected with the highly pathogenic street rabies virus. Meawhile,we performed target prediction and functional enrichment of

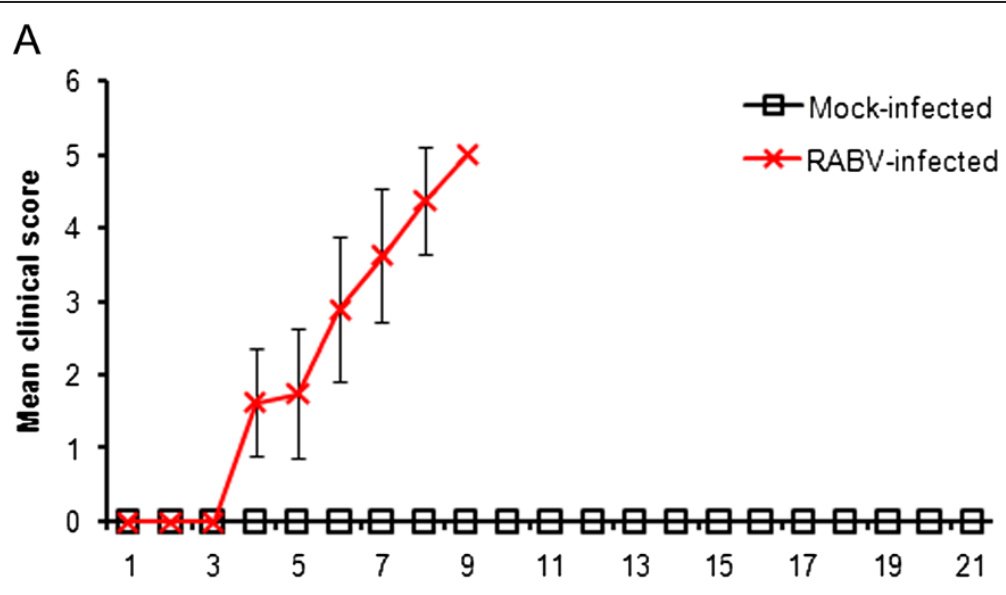

B

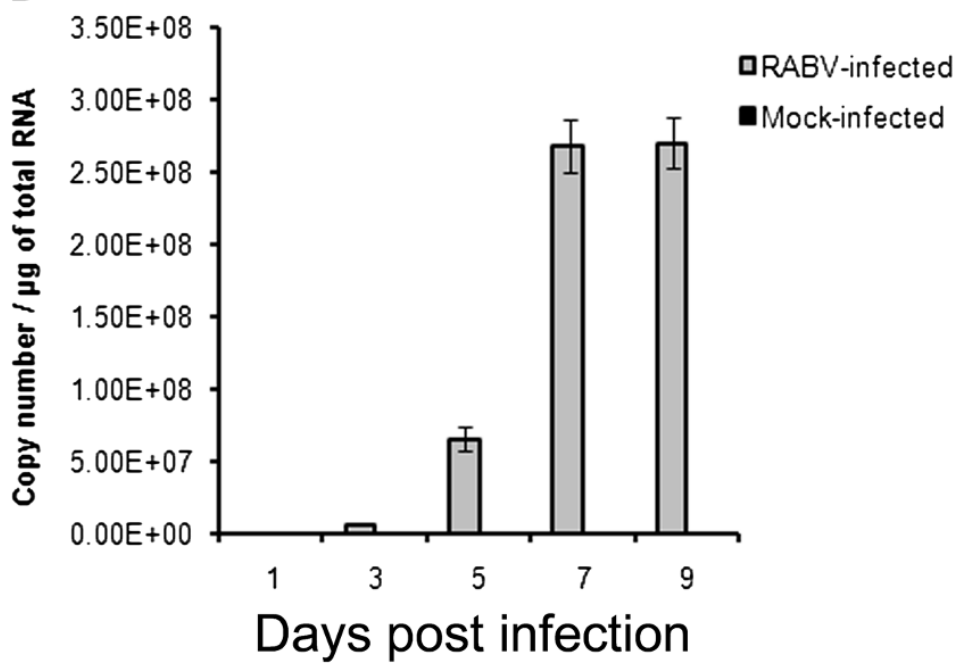

Figure 1 Outcomes of mice infected with RABV Fujian strain. After i.c. injection of $10^{5} \mathrm{ffu}$ of street Fujian RABV strain, (A) clinical score and (B) copy number of RABV N mRNA were recorded as described in Materials and Methods. Mice were monitored for survival for 21 days. Data were obtained from 8 mice (three mice for $N$ mRNA) in each group. Data are the mean \pm standard deviation (SD) of one representative experiment. Similar results were obtained in three independent experiments. 
the differentially expressed miRNAs. It was shown that several miRNAs were modulated in mouse brains infected with RABV. Finally, we performed gene microarray analysis and qRT-PCR measurement to verify the expression levels of the predicted targets of the modulated miRNAs in these pathways. The results of functional enrichment revealed that many of the predicted targets of these miRNAs play key roles in the immune response, which are known to be associated with the pathogenesis of RBAV.

\section{Results}

\section{Characterization of pathogenicity of RABV Fujian strain in mice}

All infected animals showed RABV-specific symptoms that increased in severity in a time-dependent manner. After inoculation, all mice developed the clinical signs of disordered movement at 4 days post-infection (dpi). At 6 dpi, considerable aggravation of typical clinical signs was observed, with the onset of trembling, shaking, anger, and hyperexcitation followed by general paralysis (Figure 1A). As presented in a previous study, out of all infected animals, $12.5 \%, 25 \%$, and $50 \%$ were dead at 6,7 , and $8 \mathrm{dpi}$, respectively, and all mice succumbed to RABV at or before $9 \mathrm{dpi}$ [18]. Viral load in the brain was monitored up to 9 dpi using Taqman qRT-PCR (Figure 1B). RABV replicated rapidly in brain with an increase in copy number from $3 \mathrm{dpi}$ and reached a maximal viral load at $7 \mathrm{dpi}$. The results demonstrate that the RABV Fujian strain is highly pathogenic in mice.

\section{Modulation of miRNA profile in brain in response to RABV infection}

To determine changes in miRNA expression in mouse brains in response to street RABV infection, we evaluated miRNA expression profiles at $7 \mathrm{dpi}$. The two-way hierarchical cluster heat map clear showed different expression pattern of host miRNAs between RABV and mock infections (Figure 2A). MiRNAs whose relative expression levels showed a fold change (FC) $\geq 2$ and $P \leq 0.01$ were considered significantly up-regulated, and those with $\mathrm{FC} \leq-2$ and $P \leq 0.01$ were considered significantly down-regulated. As shown in Figure 2B, nine miRNAs, miR-691, miR-377, miR-1935, miR-190, miR-1902, miR-135a*, miR-203, miR2138, and miR-290-5p, were found to be significantly upregulated. However, only one miRNAs, miR-145, was found to be down-regulated upon RABV infection. This indicates that host miRNAs were modulated in the CNS upon infection with street rabies virus.

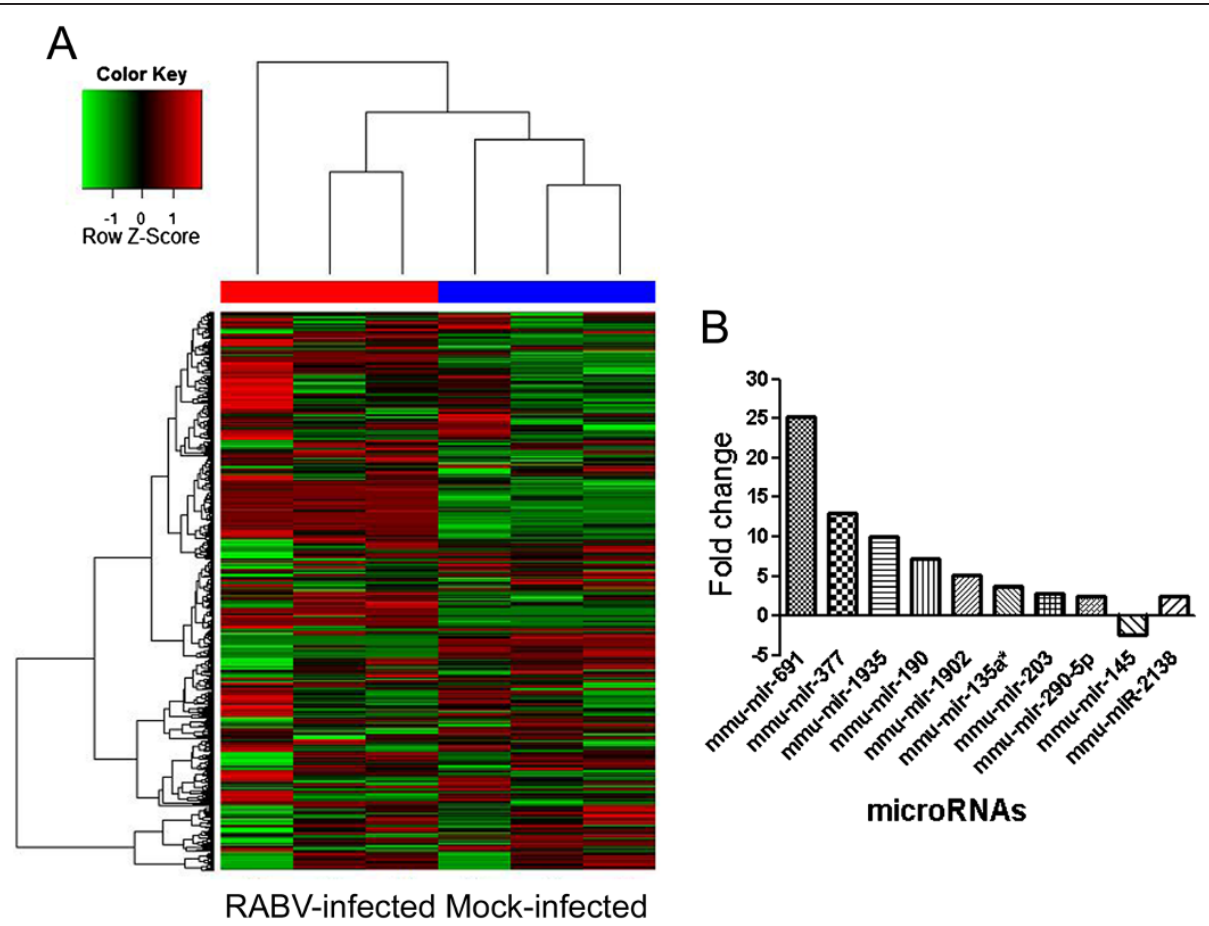

Figure 2 MiRNA profile of street RABV-infected mouse brain. (A) Two-way hierarchical cluster heat map showing all significantly expressed miRNAs in three independent samples $(P<0.01)$. Each row shows the relative expression level of a single miRNA. Each column shows the expression level of a single sample. Up-regulated miRNAs are shown in red and down-regulated miRNAs are shown in green. Significantly differentially expressed miRNAs in mouse brain upon RABV infection by microarray analysis. MiRNAs whose relative expression levels showed a fold change $(F C) \geq 2$ and $P \leq 0.01$ were considered significantly up-regulated, and those with $F C \leq-2$ and $P \leq 0.01$ were considered significantly down-regulated. 


\section{Confirmation of differentially expressed miRNAs by qRT-PCR}

To validate the differential expression profiles of miRNAs obtained by microarray analysis, quantitative RT-PCR was performed on six selected differentially expressed miRNAs including miR-691, miR-377, miR-1935, miR-190, miR203, and miR-145. The data demonstrate that the overall results of qRT-PCR were consistent with those of the microarray analysis. Although differences were observed between these two types of analysis due to intrinsic differences between the techniques, the qRT-PCR results showed the same relative regulation of differentially expressed miRNAs as the microarray data results (Figure 3).

\section{Target prediction and functional analysis of differentially expressed miRNAs}

Target genes regulated by these differentially expressed miRNAs were predicted using TargetScan Mouse, MicroCosm, and miRanda. For these ten differentially expressed miRNAs, TargetScan predicted 2,058, MicroCosm predicted 5,433 and miRanda predicted 29,742 target genes. Of these, 3,038 target genes were predicted under all three systems (Additional file 1: Figure S1). Gene ontology (GO) analysis in the Database for Annotation, Visualization and Integrated Discovery (DAVID) was performed for these miRNAs using the predicted gene targets [19]. Functional analysis revealed 106 GO terms to be involved in biological processes, 14 in

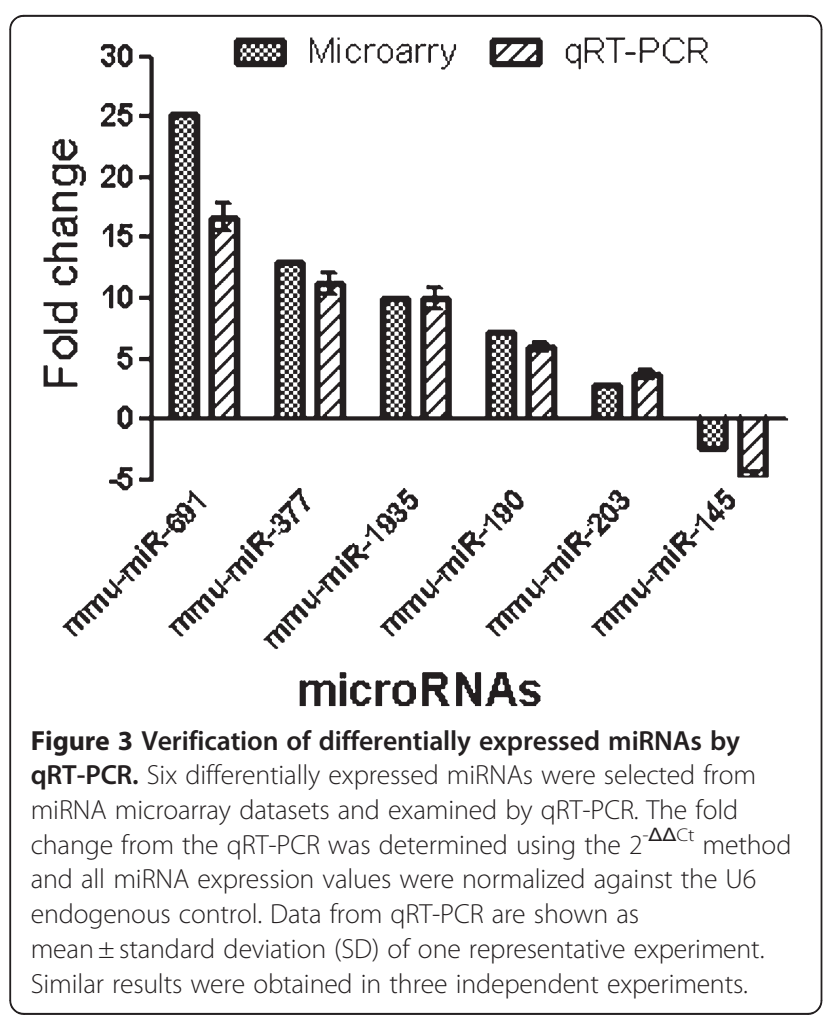

molecular function, and 20 in cellular components $(P<0.01)$ (Additional file 2: Table S1). The twenty most common GO categories were cellular processes, metabolic processes, cellular metabolic processes, macromolecule metabolic processes, and cellular macromolecule metabolic process (Figure 4). These analyses suggest that cellular miRNAs may regulate cellular metabolic processes during street RABV infection, either directly or indirectly.

\section{Pathway analysis of target genes of differentially expressed miRNAs}

To identify the biological pathways that become active in the mouse brain in response to RABV infection, we mapped the target genes of differentially expressed miRNAs to canonical signaling pathways in the Kyoto Encyclopedia of Genes and Genomes (KEGG). The results showed that 25 statistically remarkable categories $(P<0.05)$ were enriched (Additional file 3: Table S2). As shown in Table 1, the predicted target genes of six upregulated miRNAs, miR-691, miR-377, miR-1935, miR190, miR-203, and miR-135a*, and one down-regulated miRNA, miR-145, were found to be involved in immune-related pathways, such as the Jak-STAT signaling pathway, MAPK signaling pathway, Fc gamma Rmediated phagocytosis and cytokine-cytokine receptor interactions. The predicted target genes of five upregulated miRNAs, miR-691, miR-377, miR-190, miR-203, and miR-1290-5p, and one down-regulated miRNA, miR145 , were found to be involved in other pathways, such as the Adherens junction, Wnt signaling pathway, Axon guidance, cell cycle, TGF-beta signaling pathway, and Focal adhesion.

\section{DNA microarray assay and qRT-PCR measurement of miRNA targets}

MiRNAs predominately function as repressors of target gene expression. The miRNAs and their targets show mutually antagonistic expression levels. To determine whether any such correlation exists between deregulated miRNA levels and their corresponding targets, we performed DNA microarray assay and qRT-PCR validation. To identify the genes involved in the pathways common to miRNA target prediction and RABV infection, we measured the expression of genes from Jak-STAT signaling pathway (SOCS4), cytokine-cytokine receptor interactions (IL25, CD40, VEGFA, and CCR10), MAPK signaling pathway (MAPKAPK3), Fc gamma R-mediated phagocytosis (ARF6), and Wnt signaling pathway (NFAT5). As presented in Table 2, MAPKAPK3 and IL25, the targets of up-regulated miRNA miR-691; SOCS4, the target of up-regulated miRNAs miR-377; CCR10 and NFAT5, the targets of up-regulated miRNA miR-1935; VEGFA, the target of up-regulated miRNA miR- 


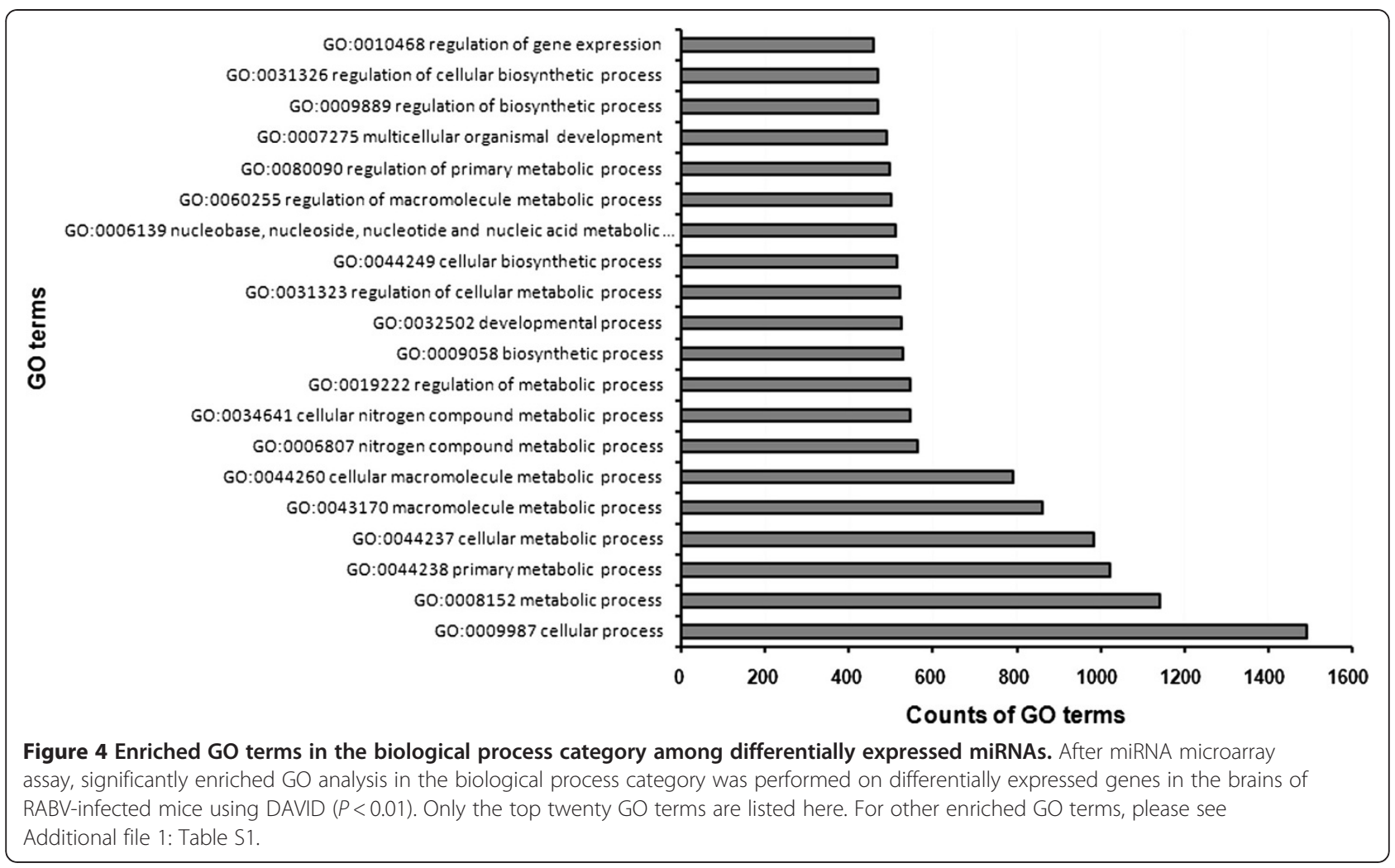

203; and $C D 40$, the target of up-regulated miRNA miR290-5p, were found to be down-regulated. ARF6, the target of down-regulated miRNA miR-145, was found to be up-regulated. The negative correlation between these miRNAs and their targets showed these pathways to be part of the RABV infection response at the expression level. Together, these results strongly suggest that certain miRNAs may be associated with RABV infection and pathogenesis.

\section{Discussion}

RABV, a pathogen well-adapted to the nervous system, infects the neurons of warm-blooded animals. Despite the catastrophic clinical outcome of RABV encephalomyelitis, especially that caused by street viruses, the histopathological changes observed in the CNS are typically relatively mild. CNS has more intrinsic mechanisms for controlling immune response than other organs. Indeed, many viral infections can be cleared from the CNS by immune mechanisms [20]. This may indicate that, upon viral infection, the immune privilege of the CNS is not as strong as has been proposed [21].

In mammals, approximately $30 \%$ of all protein-coding genes are predicted to be regulated by miRNAs [22]. Currently, nearly a thousand miRNAs have been cloned, each potentially regulating hundreds of genes by complementary binding to the 3 '-untranslated region ( $3^{\prime}$-UTR) of the target mRNAs. Recent publications have provided compelling evidence that a range of miRNAs are involved in the regulation of immunity, including the development and differentiation of $\mathrm{B}$ and $\mathrm{T}$ cells, proliferation of monocytes and neutrophils, antibody switching and the release of inflammatory mediators [4,23-25]. More importantly, researchers have reported that cellular miRNAs play key regulatory roles during viral infection and that altered cellular miRNA expression in response to viral infection may be an important determinant of virulence $[10,11,26]$.

Recently, our findings suggested that infection with laboratory-fixed rabies virus strain, ERA, induced modulation of microRNA profile of mouse brains [17]. In the current study, a comprehensive examination of miRNA expression from brains of street-RABV- and mockinfected mice was performed. The results showed that host miRNAs were modulated upon RABV infection. We found that the expression profiles of host miRNAs in mouse brains infected by these two strains of RABVs were completely different from each other. Interestingly, the same differences in transcriptome were observed between the mouse brains upon infection with the two strains of RABVs, ERA and street RABV Fujian strain (unpublished data) [18]. This discrepancy can be partly attributed to differences in virulence of the viruses. Further study is required to determine the correlation between specific miRNA expression and RABV virulence using reverse genetics or RNA interference. Some 
Table 1 Predicted targets of modulated miRNAs upon RABV infection involved in immune response pathways

\begin{tabular}{|c|c|c|c|c|}
\hline miRNA & KEGG pathway & Target genes & $\begin{array}{l}\text { Number of } \\
\text { targets }\end{array}$ & $P$ value \\
\hline mmu-miR-377 & mmu04630: Jak-STAT signaling pathway & CSF2RB2, EP300, JAK2, SOCS4, BCL2L & 5 & 0.01 \\
\hline mmu-miR-377 & mmu04010: MAPK signaling pathway & CACNA2D1, FASL, PPM1A, PPP3R1, RASA1, FLNC, PLA2G4A, SRF & 8 & 0.02 \\
\hline mmu-miR-377 & $\begin{array}{l}\text { mmu04060: Cytokine-cytokine receptor } \\
\text { interaction }\end{array}$ & CSF2RB2, FASL, ACVR2A, VEGFA, IL 18RAP, KITL, PDGFRA, LTB & 8 & 0.001 \\
\hline mmu-miR-377 & $\begin{array}{l}\text { mmu04666: Fc gamma R-mediated } \\
\text { phagocytosis }\end{array}$ & WASF1, LIMK1, PRKCD, PLA2G4A, RPS6KB1 & 5 & 0.01 \\
\hline mmu-miR-377 & mmu04520: Adherens junction & WASF1, EP300, YES1, PVRL4, PTPRB, SMAD4 & 6 & $1.18 \mathrm{E}-06$ \\
\hline mmu-miR-377 & mmu04310: Wnt signaling pathway & $\begin{array}{l}\text { EP300, WNT5A, PPP3R1, FZD3, FZD4, AXIN1, BTRC, SMAD4, } \\
\text { CUL1, DKK1 }\end{array}$ & 10 & $3.62 \mathrm{E}-04$ \\
\hline mmu-miR-377 & mmu04360: Axon guidance & PPP3R1, RASA1, LIMK1, SEMA6A, SEMA3D & 5 & 0.001 \\
\hline mmu-miR-377 & mmu04110: Cell cycle & EP300, ESPL1, CDC26, CUL1 & 4 & 0.007 \\
\hline mmu-miR-377 & mmu04350: TGF-beta signaling pathway & EP300, ACVR2A, THBS1, PITX2, SMAD4, CUL1, LEFTY2, RPS6KB1 & 8 & $6.96 \mathrm{E}-06$ \\
\hline mmu-miR-377 & mmu04510: Focal adhesion & MYLK2, XIAP, ITGA6, VEGFA, THBS1, PDGFRA, FLNC, LAMC1 & 8 & 0.018 \\
\hline mmu-miR-691 & mmu04630: Jak-STAT signaling pathway & GHR, SPRY2, TYK2, SPRED2, IL12A, CLCF1 & 6 & 0.01 \\
\hline mmu-miR-691 & mmu04010: MAPK signaling pathway & PLA2G10, MKNK2, MAPKAPK3, CACNB2, TGFBR2, DUSP9 & 5 & 0.02 \\
\hline mmu-miR-691 & $\begin{array}{l}\text { mmu04060: Cytokine-cytokine receptor } \\
\text { interaction }\end{array}$ & GHR, ACVR2A, BMP2, IL25, AMHR2, IL12A, TGFBR2, TNFSF14, CLCF1 & 9 & 0.001 \\
\hline mmu-miR-691 & $\begin{array}{l}\text { mmu04666:Fc gamma R-mediated } \\
\text { phagocytosis }\end{array}$ & $\angle Y N, I N P P 5 D$ & 2 & 0.01 \\
\hline mmu-miR-691 & mmu04520: Adherens junction & CSNK2B, SRC, CDH1, TGFBR2 & 4 & $1.18 \mathrm{E}-06$ \\
\hline mmu-miR-691 & mmu04310: Wnt signaling pathway & DKK2, CSNK2B, CAMK2G, CTBP2, VANGL1 & 5 & $3.62 \mathrm{E}-04$ \\
\hline mmu-miR-691 & mmu04360: Axon guidance & PTK2, SEMA6D, ABLIM1, NRP1, PLXNA2, SRGAP3, SEMA5A & 7 & 0.001 \\
\hline mmu-miR-691 & mmu04110: Cell cycle & YWHAB, TFDP1 & 2 & 0.007 \\
\hline mmu-miR-691 & mmu04350: TGF-beta signaling pathway & ACVR2A, BMP2, THBS1, AMHR2, TFDP1, SP1, TGFBR2 & 7 & $6.96 \mathrm{E}-06$ \\
\hline mmu-miR-691 & mmu04510: Focal adhesion & PTK2, IBSP, ITGA10, PGF, CAPN2, THBS1, SRC & 7 & 0.018 \\
\hline mmu-miR-1935 & mmu04630: Jak-STAT signaling pathway & LIFR, SPRY3 & 2 & 0.01 \\
\hline mmu-miR-1935 & mmu04010: MAPK signaling pathway & MAP3K12, FLNC, MAPT & 3 & 0.02 \\
\hline mmu-miR-1935 & $\begin{array}{l}\text { mmu04060: Cytokine-cytokine receptor } \\
\text { interaction }\end{array}$ & ACVR1, HGF, LIFR, CCR10 & 4 & 0.001 \\
\hline mmu-miR-1935 & $\begin{array}{l}\text { mmu04666: Fc gamma R-mediated } \\
\text { phagocytosis }\end{array}$ & MARCKS & 1 & 0.01 \\
\hline mmu-miR-1935 & mmu04520: Adherens junction & YEST, PVRL1 & 2 & $1.18 \mathrm{E}-06$ \\
\hline mmu-miR-1935 & mmu04310: Wnt signaling pathway & NFAT5 & 1 & $3.62 \mathrm{E}-04$ \\
\hline mmu-miR-1935 & mmu04360: Axon guidance & NFAT5, PLXNA4, SRGAP2, DCC & 4 & 0.001 \\
\hline mmu-miR-1935 & mmu04110: Cell cycle & STAG1, CDKN1C & 2 & 0.007 \\
\hline mmu-miR-1935 & mmu04510: Focal adhesion & FLNC & 1 & 0.018 \\
\hline mmu-miR-190 & mmu04630: Jak-STAT signaling pathway & 126 & 1 & 0.01 \\
\hline mmu-miR-190 & mmu04010: MAPK signaling pathway & FASL, PLA2G6, BDNF, FGF14 & 4 & 0.02 \\
\hline mmu-miR-190 & $\begin{array}{l}\text { mmu04060: Cytokine-cytokine receptor } \\
\text { interaction }\end{array}$ & FASL, HGF, IL6, CXCL16 & 4 & 0.001 \\
\hline mmu-miR-190 & $\begin{array}{l}\text { mmu04666: Fc gamma R-mediated } \\
\text { phagocytosis }\end{array}$ & PLA2G6, ARPC5 & 2 & 0.01 \\
\hline mmu-miR-190 & mmu04520: Adherens junction & SMAD2, TJP1 & 2 & $1.18 \mathrm{E}-06$ \\
\hline mmu-miR-190 & mmu04310: Wnt signaling pathway & SMAD2, PPP2R1B, ROCK1, PLCB1 & 4 & $3.62 \mathrm{E}-04$ \\
\hline mmu-miR-190 & mmu04360: Axon guidance & EPHA1, ROCK1 & 2 & 0.001 \\
\hline mmu-miR-190 & mmu04110: Cell cycle & SMAD2, CHEK1, RBL1 & 3 & 0.007 \\
\hline
\end{tabular}


Table 1 Predicted targets of modulated miRNAs upon RABV infection involved in immune response pathways (Continued)

\begin{tabular}{|c|c|c|c|c|}
\hline mmu-miR-190 & mmu04350: TGF-beta signaling pathway & SMAD2, PPP2R1B, PITX2, ROCK1, RBL1 & 5 & $6.96 \mathrm{E}-06$ \\
\hline mmu-miR-190 & mmu04510: Focal adhesion & CAPN2, HGF, ROCK1 & 3 & 0.018 \\
\hline mmu-miR-135a* & mmu04630: Jak-STAT signaling pathway & EP300,IL24,IFNAR2,IL12RB1,IFNG & 5 & 0.01 \\
\hline mmu-miR-135a* & $\begin{array}{l}\text { mmu04060: Cytokine-cytokine receptor } \\
\text { interaction }\end{array}$ & IL24,IFNAR2,IL12RB1,IFNG,CXCL16,CD4OLG & 6 & 0.001 \\
\hline mmu-miR-135a* & $\begin{array}{l}\text { mmu04666: Fc gamma R-mediated } \\
\text { phagocytosis }\end{array}$ & NCF1 & 1 & 0.01 \\
\hline mmu-miR-135a* & mmu04520: Adherens junction & EP300, ACTN2 & 2 & $1.18 \mathrm{E}-06$ \\
\hline mmu-miR-135a* & mmu04310: Wnt signaling pathway & EP300, WNT1, PPP2R1A & 3 & $3.62 \mathrm{E}-04$ \\
\hline mmu-miR-135a* & mmu04110: Cell cycle & EP300, YWHAQ, ANAPC7 & 3 & 0.007 \\
\hline mmu-miR-135a* & mmu04350: TGF-beta signaling pathway & EP300, BMP4, IFNG, PPP2R1A & 4 & $6.96 \mathrm{E}-06$ \\
\hline mmu-miR-135a* & mmu04510: Focal adhesion & PTEN, ITGA8, ACTN2 & 3 & 0.018 \\
\hline mmu-miR-290-5p & mmu04630: Jak-STAT signaling pathway & IL13RA1, IFNGR2, AKT1, CSF2RB & 4 & 0.01 \\
\hline mmu-miR-290-5p & mmu04010: MAPK signaling pathway & GADD45A, MAPKAPK3, MEF2C, MAP3K1, AKT1FGF23 & 5 & 0.02 \\
\hline mmu-miR-290-5p & $\begin{array}{l}\text { mmu04060: Cytokine-cytokine receptor } \\
\text { interaction }\end{array}$ & IL13RA1, IL18R1, CD40, IFNGR2, CXCL12, ACVR1B, CSF2RB & 7 & 0.001 \\
\hline mmu-miR-290-5p & $\begin{array}{l}\text { mmu04666: Fc gamma R-mediated } \\
\text { phagocytosis }\end{array}$ & MARCKS, AKT1 & 2 & 0.01 \\
\hline mmu-miR-290-5p & mmu04520: Adherens junction & LMO7, ERBB2, PTPRB, LEF1, INSR, SSX2IP, PVRL3 & 7 & $1.18 \mathrm{E}-06$ \\
\hline mmu-miR-290-5p & mmu04310: Wnt signaling pathway & LEF1, CAMK2G, PLCB1, AXIN2 & 4 & $3.62 \mathrm{E}-04$ \\
\hline mmu-miR-290-5p & mmu04360: Axon guidance & ROBO1, L1CAM, SEMA5B, CXCL12 & 4 & 0.001 \\
\hline mmu-miR-290-5p & mmu04110: Cell cycle & SMC3, MCM5, GADD45A, CDC25A, TFDP1, HDAC2, RAD21, ORC5L & 8 & 0.007 \\
\hline mmu-miR-290-5p & mmu04350: TGF-beta signaling pathway & TFDP1 & 1 & $6.96 \mathrm{E}-06$ \\
\hline mmu-miR-290-5p & mmu04510: Focal adhesion & $X I A P, E R B B 2, A K T 1$ & 3 & 0.018 \\
\hline mmu-miR-203 & mmu04630: Jak-STAT signaling pathway & IL24, CNTFR, IL22RA2, CCND1, SOCS3, AKT2, IL12B & 7 & 0.01 \\
\hline mmu-miR-203 & mmu04010: MAPK signaling pathway & $\begin{array}{l}\text { CACNA2D1, MAP3K13, DUSP5, MAP4K3, STK3, NLK, AKT2, ATF2, } \\
\text { PDGFRA, RAP1A, MAPT, MAP3K1, PPM1B, FGF7, CRK, PRKCA }\end{array}$ & 16 & 0.02 \\
\hline mmu-miR-203 & $\begin{array}{l}\text { mmu04060: Cytokine-cytokine receptor } \\
\text { interaction }\end{array}$ & MET, IL24, CNTFR, ACVR2A, IL22RA2, VEGFA, XCL1, PDGFRA, IL12B & 9 & 0.001 \\
\hline mmu-miR-203 & $\begin{array}{l}\text { mmu04666: Fc gamma R-mediated } \\
\text { phagocytosis }\end{array}$ & PLD2, AKT2, DNM1L, PPAP2B, CRK, VAV3, PRKCA & 7 & 0.01 \\
\hline mmu-miR-203 & mmu04520: Adherens junction & MET, NLK, SRC, PTPRB, SNAI2 & 5 & $1.18 \mathrm{E}-06$ \\
\hline mmu-miR-203 & mmu04310: Wnt signaling pathway & SFRP2, CCND1, NLK, APC, CSNK1A1, CUL1, PRKCA & 7 & $3.62 \mathrm{E}-04$ \\
\hline mmu-miR-203 & mmu04360: Axon guidance & MET, ABLI, SEMA3A, SEMA6A, SEMA5A & 5 & 0.001 \\
\hline mmu-miR-203 & mmu04110: Cell cycle & YWHAQ, CCND1, ABL1, SKP2, CUL1 & 5 & 0.007 \\
\hline mmu-miR-203 & mmu04350: TGF-beta signaling pathway & ACVR2A, ID2, BMP5, CUL1, ID4 & 5 & $6.96 \mathrm{E}-06$ \\
\hline mmu-miR-203 & mmu04510: Focal adhesion & $\begin{array}{l}\text { MET, PXN, CCND1, VEGFA, PPP1C, SRC, PDGFRA, RAP1A, RAPGEF1, } \\
\text { TNC, COL4A4, CAV1, CRK, VAV3, PRKCA }\end{array}$ & 15 & 0.018 \\
\hline mmu-miR-145 & mmu04630: Jak-STAT signaling pathway & MYC, STAM, STAT4, SOCS7 & 4 & 0.01 \\
\hline mmu-miR-145 & mmu04010: MAPK signaling pathway & $\begin{array}{l}\text { MAP3K3, HSPA1L, PPP3CA, DUSP4, MYC, RASA2, RAPGEF2, FLNB, } \\
\text { DUSP6, TGFBR2, MAP4K4, CRKL }\end{array}$ & 12 & 0.02 \\
\hline mmu-miR-145 & $\begin{array}{l}\text { mmu04060: Cytokine-cytokine receptor } \\
\text { interaction }\end{array}$ & FLT3L, TNFRSF11B, IL17RB, INHBB, ACVR1B, TGFBR2 & 6 & 0.001 \\
\hline mmu-miR-145 & $\begin{array}{l}\text { mmu04666:Fc gamma R-mediated } \\
\text { phagocytosis }\end{array}$ & ARF6, CFL2, LAT, ARPC5, CRKL & 5 & 0.01 \\
\hline mmu-miR-145 & mmu04520: Adherens junction & YES1, ERBB2, CTNND1, ACTG1, SMAD3, ACTB, TGFBR2 & 7 & 1.18E-06 \\
\hline mmu-miR-145 & mmu04310: Wnt signaling pathway & PPP3CA, FZD9, MYC, CTNNBIP1, SMAD3, SENP2, WNT5B & 7 & $3.62 \mathrm{E}-04$ \\
\hline
\end{tabular}


Table 1 Predicted targets of modulated miRNAs upon RABV infection involved in immune response pathways (Continued)

\begin{tabular}{lll}
\hline mmu-miR-145 & mmu04360: Axon guidance & PPP3CA, CFL2, SRGAP1, DPYSL2, SEMA3, EFNB3, SRGAP2, ABLIM2, \\
& & SEMA6A, PLXNA2, SEMA3D \\
mmu-miR-145 & mmu04110: Cell cycle & MCM5, MYC, SMAD3, CDK6, SFN, ORC2L \\
mmu-miR-145 & mmu04350: TGF-beta signaling pathway & MYC, SMAD3, INHBB, TGFBR2, SMAD5 \\
mmu-miR-145 & mmu04510: Focal adhesion & ERBB2, ACTG1, FLNB, ACTB \\
\hline
\end{tabular}

studies have also used profiling technology to evaluate the modulations in miRNA expression that occur in response to viral infection. For example, $\mathrm{Li}$ and colleagues performed miRNA profiling in the lungs of mice infected with influenza and found that cellular miRNA might be a contributing factor to the extreme virulence of the influenza virus [15]. Bhomia and colleagues suggested that host miRNAs were significantly modulated in mouse brains upon VEEV infection [16].

Although many computational approaches have been developed to predict miRNA targets using sequence information, their accuracy is limited [27-30]. To increase reliability, we used three web-based target prediction databases, TargetScan, MicroCosm, and Targets. The pathways listed in Table 1 and Additional file 3: Table S2 are among the most significant, as indicated by predictions from all three algorithms. It has been shown that miRNA-induced down-regulation of target genes provides opportunities to develop new approaches to target identification and validation using high-throughput expression profiling [31]. Gene expression profiling data have been used to identify functional targets of miRNAs [32-34]. MiRNAs and the mRNAs that they target for degradation can be expected to exhibit an inverse expression relationship. Researchers established a strategy for miRNA target identification using these inverse relationships as predicted from the paired expression profiles [35]. In our recently published work, we also identified miRNA targets using these inverse relationships as predicted from the paired expression profiles [17]. In the present study, we simultaneously collected miRNA and DNA microarray data from the same samples and compared the predicted targets of significantly modulated miRNAs to the gene expression profiles of RABV-infected mouse brains. This showed that some of the predicted miRNA targets were correlated with the mRNA expression profile.

Host defense against viral invasion requires induction of appropriate innate immune responses. Upon recognition of viral components, host cells become activated and produce type I IFN and proinflammatory cytokines [36,37]. A suitable amount of type I interferon (IFN) induces cellular resistance to viral infection and apoptosis of virus-infected cells [38]. However, viruses have developed several strategies to evade and subvert the immune responses mediated by type I IFN, including harnessing host miRNAs. A recent study demonstrated that the vesicular stomatitis virus (VSV), family Rhabdoviridae, can induce up-regulation of miR-146a, which feedback-inhibits RIG-I-dependent IFN-I production in macrophages [39]. In our study, enrichment of KEGG pathways revealed that the predicted target genes of differentially expressed miRNAs upon RABV infection may involve Jak-STAT signaling pathway. The Jak-STAT pathway is initiated in response to cytokines, such as interleukins and IFNs, and growth factors. To invasive innate immune response of host, RABV interrupts IFN Jak-STAT signaling in a manner of activation-dependent targeting of

Table 2 DNA microarray and qRT-PCR analysis of expression of miRNA targets

\begin{tabular}{llllllll}
\hline MicroRNA & $\begin{array}{l}\text { Accession } \\
\text { number }\end{array}$ & $\begin{array}{l}\text { MiRNA } \\
\text { microarray } \\
\text { (Fold: } \uparrow \text { or } \downarrow \text { ) }\end{array}$ & $\begin{array}{l}\text { qRT-PCR } \\
\text { (Fold: } \uparrow \text { or } \downarrow \text { ) }\end{array}$ & $\begin{array}{l}\text { Targets of } \\
\text { microRNAs }\end{array}$ & $\begin{array}{l}\text { Accession } \\
\text { Number }\end{array}$ & $\begin{array}{l}\text { DNA } \\
\text { microarray } \\
\text { (Fold: } \uparrow \text { or } \downarrow \text { ) }\end{array}$ & $\begin{array}{l}\text { qRT-PCR } \\
\text { (Fold: } \uparrow \text { or } \downarrow \text { ) }\end{array}$ \\
\hline mmu-miR-691 & Ml0004659 & $25.29 \times, \uparrow$ & $16.71 \pm 3.24 \times, \uparrow$ & MAPKAPK3 & NM_178907 & $1.57 \times, \downarrow$ & $10.02 \pm 4.11 \times, \downarrow$ \\
mmu-miR-691 & Ml0004659 & $25.29 \times, \uparrow$ & $16.71 \pm 3.24 \times, \uparrow$ & IL25 & NM_080729 & $1.45 \times, \downarrow$ & $12.75 \pm 2.91 \times, \downarrow$ \\
mmu-miR-377 & Ml0000794 & $12.90 \times, \uparrow$ & $11.22 \pm 2.87 \times, \uparrow$ & SOCS4 & NM_080843 & $1.35 \times, \downarrow$ & $9.52 \pm 2.56 \times, \downarrow$ \\
mmu-miR-1935 & Ml0009924 & $10.06 \times, \uparrow$ & $9.94 \pm 2.63 \times, \uparrow$ & CCR10 & NM_007721 & $1.39 \times, \downarrow$ & $4.58 \pm 2.03 \times, \downarrow$ \\
mmu-miR-1935 & Ml0009924 & $10.06 \times, \uparrow$ & $9.94 \pm 2.63 \times, \uparrow$ & NFAT5 & NM_133957 & $1.59 \times, \downarrow$ & $7.69 \pm 3.17 \times, \downarrow$ \\
mmu-miR-203 & Ml0000246 & $2.79 \times, \uparrow$ & $3.73 \pm 1.42 \times, \uparrow$ & VEGFA & NM_001025257 & $1.37 \times, \downarrow$ & $4.87 \pm 1.96 \times, \downarrow$ \\
mmu-miR-290-5p & MI0000388 & $2.44 \times, \uparrow$ & $6.79 \pm 2.31 \times, \uparrow$ & CD40 & NM_011611 & $1.3 \times, \downarrow$ & $5.43 \pm 2.76 \times, \downarrow$ \\
mmu-miR-145 & Ml0000169 & $0.40 \times, \downarrow$ & $4.82 \pm 1.58 \times, \downarrow$ & ARF6 & NM_007481 & $1.21 \times, \uparrow$ & $5.38 \pm 2.77 \times, \uparrow$ \\
\hline
\end{tabular}

Data from qRT-PCR are shown as mean \pm standard deviation (SD) of one representative experiment. Similar results were obtained in three independent experiments. 
STAT1 and STAT2 [40]. In this study, the target genes of modulated miRNAs were found to be involved in JakSTAT signaling, including JAK2, SOCS4, which are targets of miR-377; TYK2 and IL12A, targets of miR-691; IL6, a target of miR-190; IFNAR2, a target of miR-135a*; IFNGR 2 and AKT1, targets of miR-290-5p; and SOCS3 and $A K T 2$, targets of miR-203. This suggests that the JakSTAT pathway may be affected by RABV-inducible cellular miRNAs (Table 1).

Recent studies have revealed the important regulatory roles played by cytokines and their receptors in RABV infection. One study showed that over-expression of cytokine CCL3 (MIP-1 $\alpha)$ in mouse brains decreased RABV pathogenicity [41]. The same research team also demonstrated that MIP- $1 \alpha$ not only reduces viral pathogenicity but also enhances immunogenicity by recruiting dendritic cells and B cells to the sites of immunization, lymph nodes, and blood [42]. We observed that several targets of differentially expressed miRNAs are involved in cytokine-cytokine receptor interaction. These included FASL, IL18RAP, and KITL, which are targets of miR-377; IL25, IL12A, TNFSF14, and CLCF1, which are targets of miR-691; CCR10, a target of miR-1935; CXCL16, a target of miR-190; IL24, IFNG, CXCL16, and CD40LG, targets of miR-135a*; IL18R1, CD40, CXCL12, and CSF, targets of miR-290-5p; and IL24, XCL1, and IL12B, targets of miR203 (Table 1). Our findings showed that modulated miRNAs may regulate the functions of cytokines during RABV infection.

The MAPK signaling pathway has been shown to regulate the expression of genes involved in the immune response to pathogens. Viral infection can induce activation of the MAPK signaling pathway [43,44]. RABV infection induces MAPK and NF- $\mathrm{KB}$ activation, which have been found to regulate chemokine expression in microglial cells [45]. Some key MAPK signaling pathway-related target genes were identified in the present study. These included SPRED2, a target of miR-691, MAP3K12, a target of miR1935, MAPKAPK3 and MAP3K1, targets of miR-290-5p, and MAP3K13, MAP4K3, and MAP3K1, targets of miR203 (Table 1). This demonstrated that RABV-induced cellular miRNAs might be involved in the MAPK signaling pathway after RABV infection.

In summary, the results of the present study provide evidence that specific miRNAs are modulated in the street-RABV-infected brain. This result was found to be completely different from the expression profiles of host miRNAs in the CNS of mice infected with the laboratory-fixed strains of RABV. Considering that this was verified by both DNA microarray and qRT-PCR, we suggest that the modulated miRNAs might affect the biological processes of cells during RABV infection. Our study suggests that host miRNAs might be an important class of targets and may play a key role in regulating gene expression in response to highly pathogenic RABV infection of the CNS.

\section{Conclusion}

In summary, our findings suggested that street RABV infection resulted in significant changes in the expression of multiple miRNAs in mouse brains. The modulated miRNAs might regulate biological processes of cells during RABV infection. The predicted target genes of these differentially expressed miRNAs are involved in immune responses in the host. MiRNA and mRNA profiles obtained in this study might help elucidate the regulatory mechanisms that mediate the host response to RABV exposure.

\section{Methods}

\section{Viruses}

RABV street rabies virus Fujian strain, isolated from a rabid dog in Fujian Province, was used for this study. Viral stocks were prepared as described elsewhere with minor modifications [46]. Briefly, Three-day-old suckling mice were intracerebrally (i.c.) infected with $30 \mu \mathrm{l}$ of viral sample. When moribund, mice were euthanized and brains were removed. A 10\% (wt/vol) suspension was prepared by homogenizing the brain in Dulbecco's modified Eagle's medium (DMEM, Gibco CA, U.S.). The homogenate was centrifuged to remove debris, and the supernatant was collected and stored at $-80^{\circ} \mathrm{C}$. The viral titers were determined in triplicate on monolayer cultures of mouse neuroblastoma cell (NA) as described previously [47].

\section{Animal infection and assessment of clinical signs}

Six-to-eight-week-old female BALB/c mice were obtained from the Changchun Institute of Biological Products, China. Animals had access to food and water ad libitum. All the experiments with live virus challenge were carried out at the bio-safety level 2 (BSL-2) facilities of the Key Laboratory of Jilin Province for Zoonosis Prevention and Control, Institute of Military Veterinary, Academy of Military Medical Sciences.

The animal experiments were conducted with prior approval from the Animal Welfare and Ethics Committee of Institute of Military Veterinary, Academy of Military Medical Sciences under the permit number (SCXK2002-018). All manipulation of the mice satisfied the requirements of the Regulations of Experimental Animal Administration of China.

Mice in the experimental mice were infected with $10^{5}$ focus-forming units (FFU) of RABV in $30 \mu \mathrm{l}$ of DMEM via the i.c. route. Mice in the control group were mockinfected i.c. with DMEM containing uninfected brain homogenates for use as controls. Infected animals were observed twice daily for 21 days for the development of 
rabies. Disease progression and mortality were monitored. Clinical signs were scored as described elsewhere using a scale of 0 to 5: 0 , no clinical signs; 1 , disordered movement; 2 , ruffled fur, hunched back; 3 , trembling and shaking; 4, complete loss of motion (complete paralysis); 5, death [48].

\section{Tissue collection and total RNA isolation}

Tissue collection and total RNA isolation were performed as described elsewhere [18]. Briefly, mice at $7 \mathrm{dpi}$ were anesthetized with ketamine-xylazine (1.98 and $0.198 \mathrm{mg}$ per mouse, respectively) and euthanized. Brains were harvested and stored in RNAlater (Ambion TX, U.S.) at $-80^{\circ} \mathrm{C}$ for total RNA extraction. Total RNAs were isolated from the entire homogenized brains using the mirVana ${ }^{\mathrm{TM}}$ miRNA Isolation Kit (Ambion TX, U.S.). The integrity of total RNA was analyzed by Agilent 2100 Bioanalyzer (Agilent Technologies, CA, U.S.).

\section{Taqman PCR quantification of viral loads}

To determine viral load in infected brain tissues, TaqMan qRT-PCR was performed on RNA samples using Custom TaqMan ${ }^{\circledR}$ Gene Expression Assays (Applied Biosystems, CA, U.S.). The primers specific to the $\mathrm{N}$ gene of the RABV Fujian strain (forward: 5'-GTGGGTACTGT TGTCACTGCTTA-3' and reverse: 5'-GTGAGATTTAT CTGCTTTATGAACCCTGTA-3') and probe (FAMTCCTGAGCAATCTTC-NFQ) and the protocols for TaqMan qRT-PCR were used as described by our previous study [18]. The TaqMan PCR was performed using Brilliant II qPCR Master Mix (Agilent Technologies, CA, U.S.) in an Mx3005P apparatus (Agilent Technologies, CA, U.S.) according to the manufacturer's instructions. TaqMan runs of experimental samples contained at least three replicates with no-template or no-primer controls. Real-time PCR was performed in reaction mixtures including $12.5 \mu \mathrm{l}$ of $2 \times$ QPCR master mix (Agilent Technologies, CA, U.S.), $1 \mu \mathrm{l}$ of $20 \times$ Custom TaqMan ${ }^{\circledR}$ Gene Expression Assays (Applied Biosystems, CA, U.S.), $0.375 \mu \mathrm{l}$ of diluted reference dye (Agilent Technologies, CA, U.S.), and nuclease-free PCR-grade water to a final volume of $25 \mu \mathrm{l}$. The PCR conditions were (i) $95^{\circ} \mathrm{C}$ for 2 minutes and (ii) 40 cycles of $95^{\circ} \mathrm{C}$ for 5 seconds and $60^{\circ} \mathrm{C}$ for 20 seconds. A standard curve was generated from serially diluted RABV N RNAs of known copy numbers, and the copy numbers of samples were normalized to $1 \mu \mathrm{g}$ of total RNA. An absolute standard curve method was to calculate the copy numbers of RABV $\mathrm{N}$ mRNA in mouse brain tissue [49]. To exclude contamination of genomic DNA, control cDNA reactions in which reverse transcriptase was omitted were prepared in parallel as described elsewhere [50]. These were uniformly negative.

\section{$\mu$ Paraflo miRNA microarray assays}

Three RABV-infected and mock-infected mice at $7 \mathrm{dpi}$ were randomly selected for miRNA microarray analysis. $\mu$ Paraflo miRNA microarray assays were outsourced to LC Sciences (Houston, TX, U.S.). The assay was performed on a $5 \mu \mathrm{g}$ total RNA sample, which was sizefractionated using a YM-100 Microcon centrifugal filter (Millipore, MA, U.S.). The small RNAs (<300 nt) isolated were 3 '-extended with poly-(A) tails using poly-(A) polymerases. An oligonucleotide tag was then ligated to each poly-(A) tail for later fluorescent dye staining. Hybridization was performed overnight on a $\mu$ Paraflo microfluidic chip using a micro-circulation pump (Atactic Technologies, TX, U.S.) [51,52]. The microfluidic chips each contained a detection probe consisting of a chemically modified nucleotide coding segment complementary to target microRNA (from miRBase, http://microrna.sanger.ac.uk/sequences/) or other RNA (control or customer defined sequences) and a spacer segment of polyethylene glycol to extend the coding segment away from the substrate. The detection probes were made by in situ synthesis using PGR (photogenerated reagent) chemistry. The hybridization melting temperatures were balanced by chemical modifications of the detection probes. Hybridization used $100 \mu \mathrm{l} 6 \mathrm{xSSPE}$ buffer $(0.90 \mathrm{M} \mathrm{NaCl}$, $60 \mathrm{mM} \mathrm{Na} \mathrm{HPO}_{4}, 6 \mathrm{mM}$ EDTA, pH 6.8) containing $25 \%$ formamide at $34^{\circ} \mathrm{C}$. Post-hybridization detection used fluorescence labeling with tag-specific Cy5 dyes. Hybridization images were collected using a laser scanner GenePix 4000B (Molecular Devices) and digitized using Array-Pro image analysis software (Media Cybernetics, MD, U.S.). Raw data were obtained for further analysis.

\section{DNA microarray assays}

Three mice at $7 \mathrm{dpi}$ were randomly selected from the RABV- and mock-infected groups for DNA microarray analysis. mRNA microarray assays were outsourced to Phalanx Biotech Group. Inc. (Hsinchu, Taiwan). Fluorescencelabeled cRNA was prepared from $5 \mu \mathrm{g}$ of total RNA using a Message AMPTM aRNA Kit (Ambion, TX, U.S.) and Cy5 dye (Amersham Pharmacia, NJ, U.S.). Fluorescent targets were hybridized to the Mouse OneArray ${ }^{\mathrm{TM}}$ Whole Genome DNA microarray (Phalanx, Hsinchu, Taiwan) containing 31,802 oligonucleotides, including 29,922 mouse genome probes, and 1,880 experimental control probes. After an overnight hybridization at $50^{\circ} \mathrm{C}$, nonspecific binding targets were washed in three different washing steps, and the slides were dried by centrifugation and scanned using an GenePix 4000B (Molecular Devices, CA, U.S.). The Cy5 fluorescent intensity of each spot was analyzed using GenePix 4.1 (Molecular Devices, CA, U.S.). Raw data were obtained for further analysis. 
Table 3 Primers for selected genes analyzed using quantitative real-time PCR

\begin{tabular}{|c|c|c|c|c|}
\hline Gene symbol & Gene title & Forward primer $5^{\prime} \rightarrow 3^{\prime}$ & Reverse primer $5^{\prime} \rightarrow 3^{\prime}$ & Amplicon (bp) \\
\hline MAPKAPK3 & $\begin{array}{l}\text { Mitogen-activated protein kinase-activated } \\
\text { protein kinase } 3\end{array}$ & TATTATGTGGCTCCTGAGGTCCT & TCATCTTCCCACCCTTAGGT & 112 \\
\hline 1225 & Interleukin 25 & TGCTTGGAGCGCAGGCTCTA & AGAGAGGGTTGGCCCGTA & 113 \\
\hline SOCS4 & Suppressor of cytokine signaling 4 & ATGTTGAAATTCCTCTAAGAAG & CGTAGAACGTCAAAGACAAATT & 124 \\
\hline CCR10 & Chemokine (C-C motif) receptor 10 & ACCCAGTGTCTCCCTGATG & TTCCAGTCGGTCCCGGTTGA & 136 \\
\hline NFAT5 & Nuclear factor of activated T-cells 5 & САССТTСТСССССАТTTАТ & GTCTITCAAAAAGGGTTAA & 122 \\
\hline VEGFA & Vascular endothelial growth factor A & ССТАТТССССТСТТАAАTCGT & AGGAACTGAAGAGAGACCT & 125 \\
\hline CD40 & CD40 antigen & TCGGCTTCTTCTCCAATCAGT & TGAAATTTGGTGTCTACTGT & 126 \\
\hline ARF6 & ADP-ribosylation factor 6 & GGAAGGTGCTATCCAAGATCTT & TAACCGGGTCGAAGTTGAACAT & 108 \\
\hline GAPDH & Glyceraldehyde-3-phosphate dehydrogenase & CTCAACTACATGGTCTACATGTTC & ATTTGATGTTAGTGGGGTCTCGCTC & 142 \\
\hline
\end{tabular}

\section{Quantitative real-time PCR}

The protocols for qRT-PCR of miRNAs and mRNAs were used as described in our previous study [17]. The expression of specific miRNAs was analyzed with quantitative real-time PCR using a $\mathrm{LNA}^{\mathrm{TM}}$-based qRTPCR kit, miRCURY LNA ${ }^{\mathrm{TM}}$ Universal RT microRNA PCR System (Exiqon, Denmark) according to manufacturer's instructions. Total RNA from brain tissues of RABV-infected and mock-infected mice was converted to cDNA using universal reverse transcriptase primers (Exiqon, Denmark). cDNA samples were diluted 1:80 in nuclease-free water and then PCR was amplified using SYBR Green Master Mix and specific LNA ${ }^{\mathrm{TM}}$ miRNA primers (Exiqon, Denmark) for mmu-miR-691 (target sequence AUUCCUGAAGAGAGGCAGAAAA), mmu-miR-377 (target sequence AUCACACAAAGGCA ACUUUUGU), mmu-miR-1935 (target sequence AGG CAGAGGCUGGCGGAUCUCU), mmu-miR-190 (target sequence UGAUAUGUUUGAUAUAUUAGGU), mmumiR-203 (target sequence GUGAAAUGUUUAGGACC ACUAG), and mmu-miR-145 (target sequence GUCC AGUUUUCCCAGGAAUCCCU). Samples were run in duplicate on an Mx3005P QPCR system (Agilent Technologies, CA, U.S.). The data were normalized to a U6 RNA control (Exiqon, Denmark) and relative expression was calculated using the $2^{-\Delta \Delta C t}$ method [53].

For mRNA quantitative real-time PCR, reverse transcription was performed using a Reverse Transcription System (Promega, WI, U.S.) according to manufacturer's instructions. The names of the genes and their primers are given in Table 3. Real-time PCR was performed using Brilliant ${ }^{\circledR}$ II SYBR ${ }^{\circledR}$ Green QPCR Master Mix (Agilent Technologies, CA, U.S.) in an Mx3005P QPCR system (Agilent Technologies, CA, U.S.) according to the manufacturer's instructions. Expression of the gene of interest was normalized to glyceraldehyde-3-phosphate dehydrogenase $(G A P D H)$. The expression levels of genes were measured in terms of threshold cycle value (CT) using the $2^{-\Delta \Delta C t}$ method [53].

\section{Microarray data analysis}

Data from microarrays were analyzed as described in our previous study [17]. First, raw data from both miRNA and DNA microarrays, with replicates, were averaged. Probes with median detection $P$ value $>0.05$ and flags reported as absent were filtered out. Expression data were normalized using a variance stabilizing method VSN in a Bioconductor (http://www.bioconductor.org) [54]. Differential expression of miRNAs were assessed by eBayes (Empirical Bayes Statistics) from LIMMA [55]. Differentially expressed miRNAs with $P<0.01$ were selected for further analysis. Microarray data of miRNA and target genes were found to be MIAME compliant and have been submitted to the Gene Expression Omnibus (GEO) database (http://www. ncbi.nlm.nih.gov/geo/; accession number: GSE26269 (miRNA data); GSE26270 (mRNA data)).

\section{Target prediction and functional enrichment of differentially expressed miRNAs}

Target prediction and functional enrichment of differentially expressed miRNAs were completed as described in our previous study [17]. Three continuously updated miRNA target prediction databases, TargetScan, MicroCosm Targets, and miRanda, were used to infer the targets of differentially expressed miRNAs. The intersection of these datasets was taken as reliable. Gene ontology (GO) category and Kyoto Encyclopedia of Genes and Genomes (KEGG) pathway analyses of target genes of differentially expressed miRNAs were performed using the web-based tool, Database for Annotation, Visualization, and Integrated Discovery (DAVID, http://david.abcc.ncifcrf.gov/) ${ }^{19}$.

\section{Additional files}

Additional file 1: Figure S1. Target prediction of differentially

expressed miRNAs upon RABV infection. Three databases TargetScan, MicroCosm Targets, and miRanda, were used to infer the targets of differentially expressed miRNAs. 
Additional file 2: Table S1. Significantly enriched GO terms among targets of differentially expressed miRNAs.

Additional file 3: Table S2. Significantly enriched KEGG pathways of differential expressed miRNAs in mouse brain upon RABV infection.

\section{Abbreviations}

RABV, Rabies virus; ERA, Evelyn Rokitnicki Abelseth; CNS, Central nervous system; miRNA, microRNA; qRT-PCR, quantitative reverse transcription polymerase chain reaction; FFU, Focus-forming units; FC, Fold change; GO, Gene Ontology; KEGG, Kyoto Encyclopedia of Genes and Genomes; DAVID, Database for Annotation, Visualization and Integrated Discovery: $\mathrm{SD}$, Standard deviation.

\section{Competing interests}

The authors declare that they have no competing interests.

\section{Authors' contributions}

PSZ conceived of the study, participated in its design and coordination, drafted the manuscript, and performed the animal experiments, sample preparation, qRT-PCR, and data analysis. LLZ assisted with the propagation of virus and prepared the samples for analysis. KZ assisted with the animal infection. TCW, HLW, HF, NF, CYW, YWG, and GH participated in sample preparation. TX assisted with the analysis of the microarray data. CQ, STY, and $X Z X$ coordinated the research efforts and edited the manuscript. $X Z X$ is the corresponding author and STY is the co-corresponding author. All authors have read and approved the final manuscript.

\section{Acknowledgements}

This study was supported by the State Major Basic Research Development Program of China (Grant No. 2011CB504706) and the National Natural Science Foundation of China (Grant No. 81171555). The study sponsors had no role in the study design; in the collection, analysis, or interpretation of data; in the writing of the manuscript; or in the decision to submit the manuscript for publication.

\section{Author details}

${ }^{1}$ Institute of Laboratory Animal Sciences, Chinese Academy of Medical Sciences \& Peking Union Medical College, Beijing 100021, China. ${ }^{2}$ Key Laboratory of Jilin Province for Zoonosis Prevention and Control, Institute of Military Veterinary, Academy of Military Medical Sciences, Changchun 130122 China. ${ }^{3}$ College of Animal Science and Veterinary Medicine, Jilin University, Changchun 130062, China. ${ }^{4}$ Medical College of Soochow University, Suzhou 215123, China.

Received: 3 June 2011 Accepted: 23 July 2012

Published: 11 August 2012

\section{References}

1. Ray NB, Ewalt LC, Lodmell DL: Rabies virus replication in primary murine bone marrow macrophages and in human and murine macrophage-like cell lines: implications for viral persistence. J Virol 1995, 69:764-772.

2. Bourhy $H$, Sureau $P$, Tordo $N$ : From rabies to rabies-related viruses. Vet Microbiol 1990, 23:115-128

3. Knobel DL, Cleaveland S, Coleman PG, Fevre EM, Meltzer MI, Miranda ME, Shaw A, Zinsstag J, Meslin FX: Re-evaluating the burden of rabies in Africa and Asia. Bull World Health Organ 2005, 83:360-368.

4. Xiao C, Rajewsky K: MicroRNA control in the immune system: basic principles. Cell 2009, 136:26-36.

5. Brown $B D$, Naldini $L$ : Exploiting and antagonizing microRNA regulation for therapeutic and experimental applications. Nature reviews 2009, 10:578-585.

6. Ambros $V$ : The functions of animal microRNAs. Nature $2004,431: 350-355$

7. Brennecke J, Hipfner DR, Stark A, Russell RB, Cohen SM: bantam encodes a developmentally regulated microRNA that controls cell proliferation and regulates the proapoptotic gene hid in Drosophila. Cell 2003, 113:25-36.

8. Xu P, Vernooy SY, Guo M, Hay BA: The Drosophila microRNA Mir-14 suppresses cell death and is required for normal fat metabolism. Curr Biol 2003, 13:790-795.

9. Chen CZ, Li L, Lodish HF, Bartel DP: MicroRNAs modulate hematopoietic lineage differentiation. Science 2004, 303:83-86.
10. Ghosh Z, Mallick B, Chakrabarti J: Cellular versus viral microRNAs in host-virus interaction. Nucleic Acids Res 2009, 37:1035-1048.

11. Gottwein E, Cullen BR: Viral and cellular microRNAs as determinants of viral pathogenesis and immunity. Cell Host Microbe 2008, 3:375-387.

12. Jopling CL, Yi M, Lancaster AM, Lemon SM, Sarnow P: Modulation of hepatitis $C$ virus RNA abundance by a liver-specific MicroRNA. Science 2005, 309:1577-1581.

13. Pedersen IM, Cheng G, Wieland S, Volinia S, Croce CM, Chisari FV, David M: Interferon modulation of cellular microRNAs as an antiviral mechanism. Nature 2007, 449:919-922.

14. Huang J, Wang F, Argyris E, Chen K, Liang Z, Tian H, Huang W, Squires K, Verlinghieri G, Zhang H: Cellular microRNAs contribute to HIV-1 latency in resting primary CD4+ T lymphocytes. Nat Med 2007, 13:1241-1247.

15. Li Y, Chan EY, Li J, Ni C, Peng X, Rosenzweig E, Tumpey TM, Katze MG: MicroRNA expression and virulence in pandemic influenza virus-infected mice. J Virol 2010, 84:3023-3032.

16. Bhomia M, Balakathiresan N, Sharma A, Gupta P, Biswas R, Maheshwari R: Analysis of microRNAs induced by Venezuelan equine encephalitis virus infection in mouse brain. Biochem Biophys Res Commun 2010 395:11-16.

17. Zhao P, Zhao L, Zhang T, Wang H, Qin C, Yang S, Xia X: Changes in microRNA expression induced by rabies virus infection in mouse brains. Microb Pathog 2011, 34:503-512.

18. Zhao $P$, Zhao L, Zhang T, Qi Y, Wang T, Liu K, Wang H, Feng H, Jin H, Qin C, Yang $S$, Xia $X$ : Innate immune response gene expression profiles in central nervous system of mice infected with rabies virus. Comp Immunol Microbiol Infect Dis 2009, 37:1-3.

19. da Huang W, Sherman BT, Lempicki RA: Bioinformatics enrichment tools: paths toward the comprehensive functional analysis of large gene lists. Nucleic Acids Res 2009, 37:1-13.

20. Griffin DE: Immune responses to RNA-virus infections of the CNS. Nat Rev Immunol 2003, 3:493-502.

21. Lafon M: Modulation of the immune response in the nervous system by rabies virus. Curr Top Microbiol Immunol 2005, 289:239-258.

22. Filipowicz W, Bhattacharyya SN, Sonenberg N: Mechanisms of posttranscriptional regulation by microRNAs: are the answers in sight? Nature reviews 2008, 9:102-114.

23. Lindsay MA: microRNAs and the immune response. Trends Immuno/ 2008 , 29:343-351

24. Pedersen I, David M: MicroRNAs in the immune response. Cytokine 2008, 43:391-394.

25. Tsitsiou E, Lindsay MA: microRNAs and the immune response. Curr Opin Pharmacol 2009, 9:514-520.

26. Cullen BR: Viral and cellular messenger RNA targets of viral microRNAs. Nature 2009, 457:421-425.

27. Lewis BP, Shih $\mathrm{H}$, Jones-Rhoades MW, Bartel DP, Burge CB: Prediction of mammalian microRNA targets. Cell 2003, 115:787-798.

28. John B, Sander C, Marks DS: Prediction of human microRNA targets. Methods Mol Biol 2006, 342:101-113.

29. Maziere P, Enright AJ: Prediction of microRNA targets. Drug Discov Today 2007, 12:452-458.

30. Wang X: El Naqa IM: Prediction of both conserved and nonconserved microRNA targets in animals. Bioinformatics 2008, 24:325-332.

31. Peng $X, L i Y$, Walters KA, Rosenzweig ER, Lederer SL, Aicher LD, Proll S, Katze MG: Computational identification of hepatitis $C$ virus associated microRNA-mRNA regulatory modules in human livers. BMC Genomics 2009, 10:373.

32. Giraldez AJ, Mishima Y, Rihel J, Grocock RJ, Van Dongen S, Inoue K, Enright AJ, Schier AF: Zebrafish MiR-430 promotes deadenylation and clearance of maternal mRNAs. Science 2006, 312:75-79.

33. Linsley PS, Schelter J, Burchard J, Kibukawa M, Martin MM, Bartz SR, Johnson JM, Cummins JM, Raymond CK, Dai H, Chau N, Cleary M, Jackson AL, Carleton M, Lim L: Transcripts targeted by the microRNA-16 family cooperatively regulate cell cycle progression. Mol Cell Biol 2007, 27:2240-2252

34. Liu X, Wang T, Wakita T, Yang W: Systematic identification of microRNA and messenger RNA profiles in hepatitis $C$ virus-infected human hepatoma cells. Virology 2010, 398:57-67.

35. Jim C, Huang TB, Corson TW, Chua G, Khan S, Gallie BL, Hughes TR, Blencowe BJ, Frey BJ, Morris QD: Using expression profiling data to identify human microRNA targets. Nat Methods 2007, 4:1045-1049. 
36. Akira S, Uematsu S, Takeuchi O: Pathogen recognition and innate immunity. Cell 2006, 124:783-801.

37. Takeuchi O, Akira S: MDA5/RIG-I and virus recognition. Curr Opin Immunol 2008, 20:17-22.

38. Taniguchi T, Takaoka A: A weak signal for strong responses: interferon-alpha/beta revisited. Nat Rev Mol Cell Biol 2001, 2:378-386.

39. Hou J, Wang P, Lin L, Liu X, Ma F, An H, Wang Z, Cao X: MicroRNA-146a feedback inhibits RIG-I-dependent Type I IFN production in macrophages by targeting TRAF6, IRAK1, and IRAK2. J Immunol 2009, 183:2150-2158.

40. Brzozka K, Finke S, Conzelmann KK: Inhibition of interferon signaling by rabies virus phosphoprotein P: activation-dependent binding of STAT1 and STAT2. J Virol 2006, 80:2675-2683.

41. Zhao L, Toriumi H, Kuang Y, Chen H, Fu ZF: The roles of chemokines in rabies virus infection: overexpression may not always be beneficial. J Virol 2009, 83:11808-11818.

42. Zhao L, Toriumi H, Wang H, Kuang Y, Guo X, Morimoto K, Fu ZF: Expression of MIP-1alpha (CCL3) by a recombinant rabies virus enhances its immunogenicity by inducing innate immunity and recruiting dendritic cells and B cells. J Virol 2010, 84:9642-9648.

43. Garrington TP, Johnson GL: Organization and regulation of mitogenactivated protein kinase signaling pathways. Curr Opin Cell Biol 1999, 11:211-218.

44. Kujime K, Hashimoto S, Gon Y, Shimizu K, Horie T: p38 mitogen-activated protein kinase and c-jun-NH2-terminal kinase regulate RANTES production by influenza virus-infected human bronchial epithelial cells. J Immunol 2000, 164:3222-3228.

45. Nakamichi K, Saiki M, Sawada M, Takayama-Ito M, Yamamuro Y, Morimoto K, Kurane I: Rabies virus-induced activation of mitogen-activated protein kinase and NF-kappaB signaling pathways regulates expression of CXC and CC chemokine ligands in microglia. J Virol 2005, 79:11801-11812.

46. Yan X, Prosniak M, Curtis MT, Weiss ML, Faber M, Dietzschold B, Fu ZF: Silver-haired bat rabies virus variant does not induce apoptosis in the brain of experimentally infected mice. J Neurovirol 2001, 7:518-527.

47. Morimoto K, Patel M, Corisdeo S, Hooper DC, Fu ZF, Rupprecht CE, Koprowski H, Dietzschold B: Characterization of a unique variant of bat rabies virus responsible for newly emerging human cases in North America. Proc Natl Acad Sci U S A 1996, 93:5653-5658.

48. Faber M, Faber ML, Li J, Preuss MA, Schnell MJ, Dietzschold B: Dominance of a nonpathogenic glycoprotein gene over a pathogenic glycoprotein gene in rabies virus. J Virol 2007, 81:7041-7047.

49. Wong ML, Medrano JF: Real-time PCR for mRNA quantitation. Biotechniques 2005, 39:75-85.

50. Deng HK, Unutmaz D, KewalRamani VN, Littman DR: Expression cloning of new receptors used by simian and human immunodeficiency viruses. Nature 1997, 388:296-300.

51. Gao X, Gulari E, Zhou X: In situ synthesis of oligonucleotide microarrays. Biopolymers 2004, 73:579-596.

52. Zhu Q, Hong A, Sheng N, Zhang X, Matejko A, Jun KY, Srivannavit O, Gulari E, Gao X, Zhou X: microParaflo biochip for nucleic acid and protein analysis. Methods Mol Biol 2007, 382:287-312.

53. Schmittgen TD, Livak KJ: Analyzing real-time PCR data by the comparative C(T) method. Nat Protoc 2008, 3:1101-1108.

54. Huber W, von Heydebreck A, Sultmann H, Poustka A, Vingron M: Variance stabilization applied to microarray data calibration and to the quantification of differential expression. Bioinformatics 2002, 18(Suppl 1):S96-S104.

55. Smyth GK: Linear models and empirical bayes methods for assessing differential expression in microarray experiments. Stat Appl Genet Mol Biol 2004, 3:Article3.

doi:10.1186/1743-422X-9-159

Cite this article as: Zhao et al:: Infection with street strain rabies virus induces modulation of the microRNA profile of the mouse brain. Virology Journal 2012 9:159.

\section{Submit your next manuscript to BioMed Central and take full advantage of:}

- Convenient online submission

- Thorough peer review

- No space constraints or color figure charges

- Immediate publication on acceptance

- Inclusion in PubMed, CAS, Scopus and Google Scholar

- Research which is freely available for redistribution

Submit your manuscript at www.biomedcentral.com/submit
C Biomed Central 